\title{
The Effect of Incorporating Different Concentrations of Octenidine Dihydrochloride on the Degree of Conversion of an Experimental Flowable Resin Composite
}

\author{
Mahitab Mansour ${ }^{1 *}(\mathbb{D})$, Tarek Salah Hussein ${ }^{2}$ (D) Haidy Salem ${ }^{3}$ (D) \\ ${ }^{1}$ Department of Dental Biomaterials Science, Faculty of Dentistry, October University for Modern Sciences and Arts, Cairo, \\ Egypt; ${ }^{2}$ Department of Dental Biomaterials Science, Faculty of Dentistry, Ain-Shams University, Cairo, Egypt; ${ }^{3}$ Department of \\ Restorative and Dental Materials, National Research Center, Cairo, Egypt
}

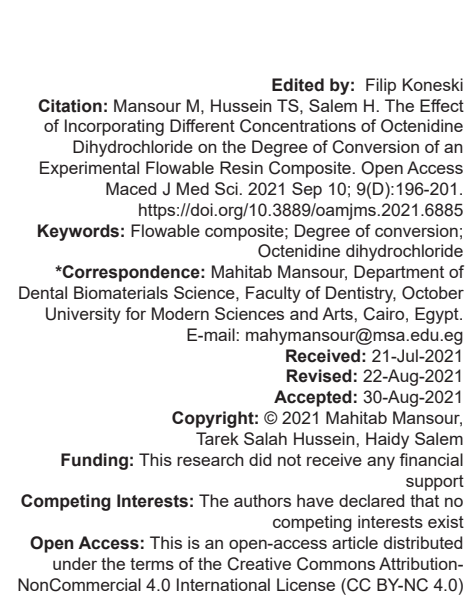

Introduction

Esthetic restorations that have the properties of matching the natural tooth color are in exceedingly high demand by both patients and dentists. Hence, many trials have been made to find the highest quality of esthetic dental restorations [1]. Resin composites have undergone numerous improvements along the years to achieve more durable esthetic restorative materials with similar mechanical and physical properties to that of the natural tooth [2], [3].

One of the important parameters in assessing the definitive physical, mechanical, and biological characteristics of resin composites is the degree of conversion (DC), as resin composite qualities have been proven to improve with increasing the DC achieved after photo-polymerization [4]. Since dental caries is an infectious disease introduced by cariogenic bacteria, attempts to develop antibacterial restorative materials became a popular issue in dental materials science [5].
Recent antimicrobial agents, such as Octenidine dihydrochloride (OCT) have been investigated as alternatives to other antibacterial agents because of their superior microbicidal activity and low cytotoxicity [6]. Accordingly, this study is designed to incorporate different concentrations of OCT into experimentally formulated flowable composite and measure their DC.

\section{Materials and Methods}

Four groups were tested in this study:

1. Group 1: The control group was a commercially available resin composite by Kerr Corporation with the brand name "Herculite Ultra Flowable"

2. Group 2: Experimental resin composite with 0 wt $\%$ OCT 
3. Group 3: Experimental resin composite with $1 \%$ OCT

4. Group 4: Experimental resin composite with $1.5 \%$ OCT

Table 1.

The materials used in this study are shown in

Table 1: Materials, presentation, manufacturer, and batch number of chemicals used in this study

\begin{tabular}{|c|c|c|c|}
\hline Material & Presentation & Manufacturer & $\begin{array}{l}\text { Batch } \\
\text { Number }\end{array}$ \\
\hline $\begin{array}{l}\text { Bisphenol A glycerolate } \\
\text { dimethacrylate, (Bis-GMA) } \\
\left(\mathrm{C}_{29} \mathrm{H}_{36} \mathrm{O}_{8}\right) \\
\text { Mol. Wt: } 512.59\end{array}$ & Viscous liquid & Sigma Aldrich, USA & 494356 \\
\hline $\begin{array}{l}\text { Triethylene glycol dimethacrylate } \\
\text { (TEGDMA) }\end{array}$ & Liquid & Sigma Aldrich, USA & 261548 \\
\hline $\begin{array}{l}\text { Trimethoxysilane }\left(\mathrm{C}_{3} \mathrm{H}_{10} \mathrm{O}_{3} \mathrm{Si}\right) \\
\text { Mol. Wt: } 122.2\end{array}$ & Liquid & Sigma Aldrich, USA & 282626 \\
\hline $\begin{array}{l}\text { Silicon dioxide nano-powder } \\
\text { (spherical) }\left(\mathrm{SiO}_{2}\right) \text {, Mol. Wt: } 60.08\end{array}$ & $\begin{array}{l}\text { Powder (size: 5-15 } \\
\mathrm{nm} \text { ) }\end{array}$ & Sigma Aldrich, USA & 637246 \\
\hline $\begin{array}{l}\text { Ethyl 4-(dimethylamino) benzoate } \\
\left(\mathrm{C}_{11} \mathrm{H}_{15} \mathrm{NO}_{2}\right) \text { Mol. Wt: } 193.24\end{array}$ & Crystalline Powder & Sigma Aldrich, USA & E24905 \\
\hline $\begin{array}{l}\text { Camphorquinone, }\left(\mathrm{C}_{10} \mathrm{H}_{14} \mathrm{O}_{2}\right) \text { Mol. } \\
\text { Wt: } 166.22\end{array}$ & Powder & Alpha Aesar, USA & 124893 \\
\hline Acetic Acid Glacial & Liquid & PioChem, Egypt & AC0121 \\
\hline Ethanol $70 \%$ & Liquid & PioChem, Egypt & Et0012 \\
\hline $\begin{array}{l}\text { Buffer solution DURACAL } \\
(\mathrm{pH} 4.01)\end{array}$ & Liquid & Sigma Aldrich, USA & 242142 \\
\hline Potassium Bromide (KBr) & Powder & Sigma Aldrich, USA & 221864 \\
\hline OCT & Powder & $\begin{array}{l}\text { MedChem Express } \\
\text { (MCE), USA }\end{array}$ & 23549 \\
\hline $\begin{array}{l}\text { Flowable composite, (Herculite } \\
\text { Ultra Flowable) }\end{array}$ & Paste & Kerr Corporation & 35408 \\
\hline
\end{tabular}

For the experimental groups, the flowable composite was formulated according to the following steps:

\section{Preparation of the experimental flowable resin composite material}

\section{Preparation of the resin matrix}

Preparation of the resin matrix was done by mixing the viscous monomer bisphenol A-glycidyl methacrylate (Bis-GMA) with the liquid monomer TEGDMA in a ratio of $70: 30 \%$ weight [7].

\section{Preparation of the photo-initiator system}

A ratio of 1:1 of the crystalline camphorquinone powder and ethyl 4-(dimethyl-amino) benzoate were used for the preparation of the photo-initiator system. The prepared photo-initiator powder was then gradually added to the dark glass beaker containing the mixture of the unfilled resin matrix. A small magnet on a magnetic stirrer (MS-300HS, Human Lab Instrument Co., Korea) was used to stir the mixture constantly for $2 \mathrm{~h}$ to ensure homogenization of all components and complete dissolution of the monomers [8]. coupling agent

Preparation and hydrolysis of the silane

Ethanol solution with a concentration of $70 \%$ was proportioned in a small glass beaker and covered with a filter paper. Drops of acetic acid were gradually added to ethanol to improve the hydrolysis rate of the silane coupling agent until the $\mathrm{pH}$ decreased to 3-4 [9], that was measured using a bench $\mathrm{pH}$ meter (Jenway,3505, UK). Afterward, 3\% wt of the liquid silane coupling agent Trimethoxysilane was added to the solution then stirred in a glass beaker covered with a paraffin film for $1 \mathrm{~h}$ using a magnetic stirrer.

The commercial silicon dioxide nanopowder was sintered at $1300^{\circ} \mathrm{C}$ for 20 min using an electric fast sintering dental furnace sintered by (TEGRA SPEED, Teknik Dental, Istanbul Turkey) The final shape of the particles after sintering appeared as white clusters. The sintered clusters were then ground using agate mortar and pestle then sieved using a stainless steel 400 mesh sieve [10].

Sintered silicone dioxide nanoparticles were immersed directly in the prepared hydrolyzed silane coupling agent solution and stirred using the magnetic stirrer for $2 \mathrm{~h}$. The mixture was then centrifuged for $30 \mathrm{~min}$, at a temperature of $25^{\circ} \mathrm{C}$, with a speed of 6000 rotation/min using a centrifugation machine (SIGMA 3-16KL, Sigma Laborzentrifugen $\mathrm{GmbH}$, Germany). The nanoparticles were deposited at the base of the clear plastic Eppendorf tube after centrifugation. The precipitate was washed with ethanol and mixed in a vortex mixer (Stuart, SA7, UK) at $1800 \mathrm{rpm}$ to ensure proper homogenous mixing, and then centrifuged again for 5 min using the same centrifugation apparatus. This process was repeated three times and the remaining ethanol was removed. The precipitate was then dried in a small petri dish using a hot air drying and heating oven (BINDER, FD 23, 20L, Germany). The heating temperature was maintained constant at $105^{\circ} \mathrm{C}$ for $60 \mathrm{~min}$ [11]. The petri dish was then removed from the oven and covered with aluminum foil and placed in a desiccator for a further $10 \mathrm{~min}$.

\section{Addition of the OCT to the silanized nano filler particles}

The OCT antibacterial agent was added to the silanized nanofillers in special dark containers at a concentration of $1 \% \mathrm{wt}$. and $1.5 \%$ wt., respectively. These concentrations were determined based on a pilot study conducted prior to the test.

\section{Addition of the fillers containing the antibacterial agent to the unfilled resin matrix}

The nanofillers mix containing the antibacterial agent was incrementally added to the experimentally prepared resin matrix [11]. The uncured resin composite mix was placed in a dark-tinted bottle, then stored in a dark place overnight, and mixed manually the next day. 


\section{Measuring the DC using the Fourier transform infrared (FTIR) spectroscopy}

According to specification n. 27 of ANSI/ADA, in 1993 [12], the cylindrical specimens with dimensions ( $5 \mathrm{~mm}$ in diameter $\times 4 \mathrm{~mm}$ thickness) were fabricated. The total number of specimens used in this study was 32 specimens, divided equally among the four groups where eight specimens were used for each group $(n=8)$, which was further subdivided into two groups where $n=$ 4 (cured) and $n=4$ (uncured) for each testing group.

Photo-activation was performed by placing the light curing device (Premium Plus light cure C02$D$, Premium PlusUK, England) on the resin composite specimens' upper surface through each side of the mold, the specimens were irradiated for $40 \mathrm{~s}$. After photo-activation, the specimens were taken from the mold and stored for $24 \mathrm{~h}$ in dry, dark containers at $37^{\circ} \mathrm{C}$ $\left( \pm 1^{\circ} \mathrm{C}\right)$ for $24 \mathrm{~h} \mathrm{[4]}$.

$24 \mathrm{~h}$ after the photoactivation, the polymerized specimens from each group were milled into a fine powder using a mortar and pestle. $5 \mathrm{mg}$ of the ground powder were mixed meticulously with $100 \mathrm{mg}$ of the $\mathrm{KBr}$ powder salt. This grounded mixture was then positioned into a pelleting device (SCHIMADZU, Kyoto, Japan) and the mix was then pressed with a pressure of $86 \mathrm{KN}$ for $1 \mathrm{~min}$ to obtain a pellet [13]. FTIR (SCHIMADZU IRAffinity-1S, Kyoto, Japan) was used to assess the DC.

The diffuse-reflection mode of the FTIR was used to record the absorbance peaks under the following conditions: 32 scans, over a wavelength of $400-4000 \mathrm{~cm}^{-1}$ and a resolution of $4 \mathrm{~cm}^{-1}$ [4], [13]. For the unpolymerized specimens $(n=4)$ of each group, the uncured material was smeared onto thin $\mathrm{KBr}$ discs, and placed into a cell holder in the spectrophotometer, to obtain a range with the same parameters as for the polymerized samples [13].

Finally, the DC was calculated by comparing the peak height ratios of the absorbance intensities of the aliphatic $\mathrm{C}=\mathrm{C}$ peak at $1638 \mathrm{~cm}^{-1}$ and an internal reference peak of aromatic $\mathrm{C}=\mathrm{C}$ at $1608 \mathrm{~cm}^{-1}$ before and after curing the specimens [13].

DC\% for each specimen was calculated using the following equation [13]

$$
\mathrm{DC} \%=\left\{1-\frac{\left(1638 \mathrm{~cm}^{-1} / 1608 \mathrm{~cm}^{-1}\right) \text { cured }}{\left(1638 \mathrm{~cm}^{-1} / 1608 \mathrm{~cm}^{-1}\right) \text { uncured }} \times 100\right.
$$

Statistical analysis was performed using a commercially available software program (SPSS 18; SPSS, Chicago, IL, USA).

The mean, standard deviation (SD), and confidence intervals were used to present the data. The Kolmogorov-Smirnov test of normality was used to examine the data for normalcy. For parametric data, a one-way analysis of variance (ANOVA) was performed to compare groups, and if a significant difference was found, Tukey's post-hoc test was utilized. The significance level was chosen at $p \leq 0.05$.

\section{Results}

The mean values of $D C$ ranged between $(70.37$ and 48.7), where Group1 showed the highest mean value, followed by group 2 than Group 3, Group 4 specimens had the lowest mean value as shown in Figure 1. ANOVA test revealed a statistically significant difference between all groups as shown in Table 2. Tukey's posthoc test revealed a significant difference between each two groups as shown in Table 3.

Table 2: Descriptive statistics of the DC\% and comparison between groups (ANOVA)

\begin{tabular}{|c|c|c|c|c|c|c|c|c|c|}
\hline \multirow[t]{2}{*}{ Groups } & \multirow[t]{2}{*}{ Mean } & \multirow[t]{2}{*}{$\begin{array}{l}\text { Std. } \\
\text { Dev }\end{array}$} & \multirow[t]{2}{*}{$\begin{array}{l}\text { Std. } \\
\text { Error }\end{array}$} & \multicolumn{2}{|c|}{$\begin{array}{l}95 \% \text { Confidence } \\
\text { Interval for Mean }\end{array}$} & \multirow[t]{2}{*}{ Min } & \multirow[t]{2}{*}{ Max } & \multirow[t]{2}{*}{$\mathrm{F}$} & \multirow[t]{2}{*}{$p$} \\
\hline & & & & $\begin{array}{l}\text { Lower } \\
\text { bound }\end{array}$ & $\begin{array}{l}\text { Upper } \\
\text { bound }\end{array}$ & & & & \\
\hline Group 1 & $70.37 a$ & 3.50 & 1.24 & 67.44 & 73.29 & 65.22 & 75.82 & 67.97 & $0.00^{*}$ \\
\hline Group 2 & $56.74 b$ & 3.15 & 1.11 & 54.10 & 59.37 & 50.49 & 60.18 & & \\
\hline Group 3 & $52.88 c$ & 2.86 & 1.01 & 50.49 & 55.27 & 49.89 & 59.02 & & \\
\hline Group 4 & $48.70 d$ & 3.34 & 1.18 & 45.91 & 51.49 & 44.98 & 53.13 & & \\
\hline
\end{tabular}

\section{Discussion}

New paradigms strive to formulate remedial resin composite materials exhibiting antibacterial effects. In this study, an antimicrobial agent OCT was incorporated into the fillers of an experimentally formulated resin composite and the DC was measured for all the tested groups.

Table 3: Detailed results of Tukey's post-hoc test for comparison of the $\mathrm{DC} \%$

\begin{tabular}{|c|c|c|c|c|c|c|}
\hline \multirow[t]{2}{*}{ I-Groups } & \multirow[t]{2}{*}{ J-Groups } & \multirow{2}{*}{$\begin{array}{l}\text { Mean } \\
\text { difference } \\
\text { (I-J) }\end{array}$} & \multirow[t]{2}{*}{ Std. Error } & \multirow[t]{2}{*}{ Sig. } & \multicolumn{2}{|c|}{ 95\% Confidence Interval } \\
\hline & & & & & Lower bound & Upper bound \\
\hline \multirow[t]{3}{*}{ Group 1} & Group2 & $13.62875^{*}$ & 1.610 & 0.000 & 9.232 & 18.025 \\
\hline & Group3 & $17.48500^{*}$ & 1.610 & 0.000 & 13.088 & 21.882 \\
\hline & Group4 & $21.66500^{*}$ & 1.610 & 0.000 & 17.268 & 26.062 \\
\hline \multirow[t]{3}{*}{ Group 2} & Group1 & $-13.62875^{\star}$ & 1.610 & 0.000 & -18.025 & -9.232 \\
\hline & Group3 & 3.85625 & 1.610 & 0.101 & -0.540 & 8.253 \\
\hline & Group4 & $8.03625^{*}$ & 1.610 & 0.000 & 3.640 & 12.433 \\
\hline \multirow[t]{3}{*}{ Group 3} & Group1 & $-17.48500^{*}$ & 1.610 & 0.000 & -21.882 & -13.088 \\
\hline & Group2 & -3.85625 & 1.610 & 0.101 & -8.253 & 0.540 \\
\hline & Group4 & 4.18000 & 1.610 & 0.067 & -0.217 & 8.577 \\
\hline \multirow[t]{3}{*}{ Group 4} & Group1 & $-21.66500^{*}$ & 1.610 & 0.000 & -26.062 & -17.268 \\
\hline & Group2 & $-8.03625^{\star}$ & 1.610 & 0.000 & -12.433 & -3.640 \\
\hline & Group3 & -4.18000 & 1.610 & 0.067 & -8.577 & 0.217 \\
\hline
\end{tabular}

OCT is a Bis(pyridine) derivative that has been suggested as an alternative to chlorhexidine based on its antimicrobial effects and lower cytotoxicity. OCT exhibits high broad-spectrum antimicrobial efficacy on both gram-positive and gram-negative bacteria, fungi, and several viral species [14]. The enhanced antimicrobial efficacy of OCT is attributed to its cation-active structure that readily binds to the negatively charged bacterial 
cell wall and thereby affects the vital functions of the cell membrane and causes cell death [15]. Based on a pilot study, the weight percentages of the OCT antibacterial agent used in this work were determined.

Because resin composite qualities have been shown to improve with increasing the DC obtained following photopolymerization, the DC is an important parameter for measuring the actual physical, mechanical, and biological features of resin composites [4].

The longevity of the resin composite restoration may also be affected by a lower DC that may result in unreacted monomers rendering them more soluble in the wet oral environment. Furthermore, reactive sites (double bonds) are also more vulnerable to hydrolyzation or oxidation and result in material degradation. Besides, uncured functional groups can also act as plasticizers, lowering the resin composite's final mechanical [4].

Furthermore, increased cure has been reported to result in a reduced quantity of leachable monomers, resulting in a more biocompatible restoration, because of the risk of biological responses associated with monomer release and pulp tissue affliction [4], [16].

The main methods commonly used to measure the DC of resin composites are the FTIR spectroscopy, the Raman and the FT-Raman spectroscopy [17]. FTIR spectroscopy was used to determine the $D C$ of the resin composites in this study. The use of an interferometer to separate the spectral components and a mathematical technique to speed up the measurement is referred to as FTIR [17].

FTIR spectroscopy depends on the absorption or reflection of light whereas Raman spectroscopy investigates the light scattering processes. It is important to note that (a) radiation absorption is much more efficient (109 times) than scattering (b) IR absorption measurements are more appropriate for polar systems who have substantial transfers between atoms or molecules, such as the chemical bonds formed by polymerization of resin monomers. Based on these considerations the FTIR was the method of choice in this study as it is the simplest and most reliable technique [17]. FTIR detects the amount of unreacted C $=\mathrm{C}$ in the resin matrix and $\mathrm{C}=\mathrm{C}$ stretching vibrations directly before and after curing of resin composite to determine changes in mechanical performance [18]

The obtained values for the DC in this study agreed with findings from other studies performed on similar systems and measured with the same method: The DC in this study ranged between $48.70 \%$ and $70.37 \%$. In 1995 Ferracane [19], found that the DC ranged between 35\% and 77\%, whereas in 1997 Peutzfeldt [20]. stated that the DC of monomer to polymer in dental resin composites varied between $40 \%$ and $75 \%$.

In the present study, all groups showed significantly different percentage values of DC. The addition of the antibacterial agent OCT significantly decreased the DC percentages in groups 2, 3, and 4, where Group 4 showed the lowest DC percentage among all tested groups. While the mean value for the control group 1 showed the highest DC percentage among all the tested groups.

The DC is regulated by a complex interaction of several factors, which during polymerization, affect the reactive species [21]. The differences in the percentages of the DC between the studied groups could be related to changes in chemical composition, because the sample sizes, curing procedure, light source, polymerization conditions, and method for measuring DC were all kept standardized between the various tested groups.

The above considerations are further complicated in the case of the experimental resin composites used in this study (groups 2, 3, and 4) could be due to the tendency of nanometre-sized silica particles to agglomerate into larger secondary particles [22], which makes it more difficult to control experimentally, and considering the fact that resin/ filler interactions vary depending on the level of filler silanization [23]. In addition, during preparation oxygen in agglomerates could inhibit free-radical polymerization in the specimen, this phenomenon has been observed in some experimental resin composite types [24].

Chemistry of filler matrix, filler particle sizes, and dispersion could interfere with the transmission of light through the material and thus interfere with proper polymerization and DC [25]. The reduction of DC values with increasing the antibacterial content in groups (3 and 4) could probably be related to the effect of light scattering by the antibacterial particles. Moreover, some reports also showed larger scattering when the particle size was approximately one half or close to that of the curing light wavelength [26].

Different sizes of the filler particles are another variable that could affect the DC of a resin composite. This is attributed to the scattering effect of tiny fillers which reduces the amount of light transmitted through the resin [18]. The commercially available (group 1) had a higher conversion rate than the other groups in this study, which could be due to unique filler combinations and different filler sizes in comparison to the other groups.

Moreover, the opacity of a substance has a considerable influence on light transmission through it [25]. The observed lower DC values corresponding to the increase in the antibacterial content in groups (3 and 4) may also be attributed to their increased opacity, reduced filler material can also help attain higher translucency between materials [25]. It has also been proven in other studies that increasing the fillerto-matrix ratio reduces conversion in experimental resin composites [27], this is also in accordance with findings in this study. 


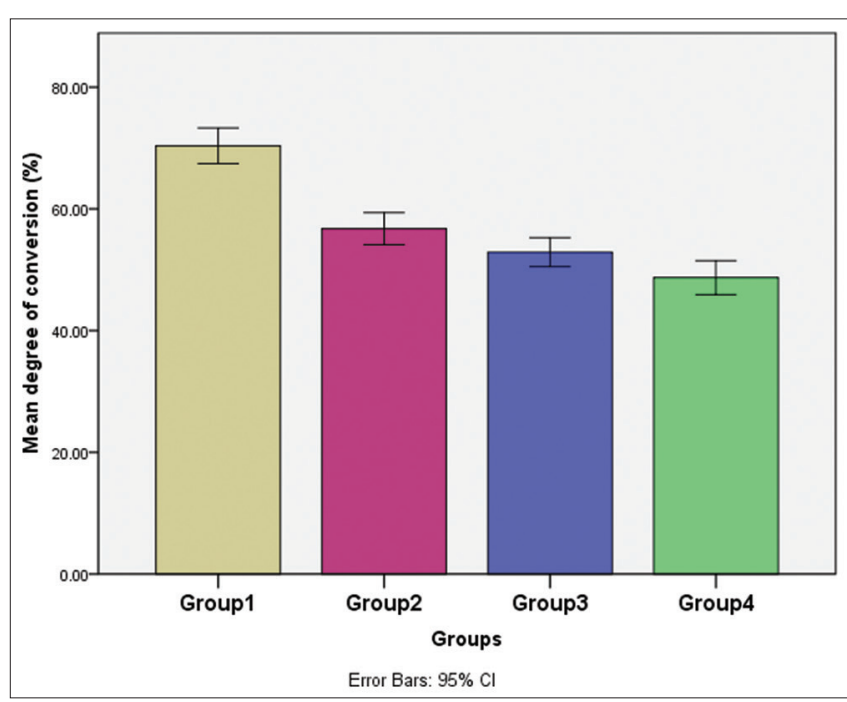

Figure 1: Bar chart illustrating mean degree of conversion $\%$ in different groups

The strengths of this study were first; the determination of the DC and the amount of residual monomers in dental resin composites are of great importance, as these parameters could be regarded as prognostic factors for the behavior of dental restorations under clinical conditions. Moreover, the antibacterial used in this study was previously used in the medical field but recently introduced into the field of dentistry and was not incorporated in flowable resin composites before, therefore it's a pioneering idea that also gave promising results.

Additionally, in vitro testing helps build a strong and original scientific record, to highlight the technological and competitive advantages of any new material. However, from the limitations of this study were that it failed to capture the inherent complexity of biological organ systems under clinical use. Adding to that, scarce literature was available for comparisons with other studies.

\section{Conclusion}

Under the limitations of the current study, adding $1 \%$ and $1.5 \%$ wt of OCT to the experimentally formulated composite resin showed satisfactory results for the $D C$ that met the ADA requirements for clinical use.

\section{References}

1. McDonald A. Albers tooth-colored restoratives: Principles and techniques. Oral Dis. 2004;10(1):61. https://doi. org/10.1046/j.1354-523x.2003.00976.x

2. MazerRB, LeinfelderKF. Evaluating amicrofill posteriorcomposite resin a five-year study. J Am Dent Assoc. 1992;123(4):32-8. https://doi.org/10.14219/jada.archive.1992.0111

3. Wendt SL Jr., Leinfelder KF. Clinical evaluation of clearfi photoposterior: 3-year results. Am J Dent. 1992;5(3):121-5. PMid:1388946

4. Galvão MR, Caldas SG, Bagnato VS, de Souza Rastelli AN, de Andrade MF. Evaluation of degree of conversion and hardness of dental composites photo-activated with different light guide tips. Eur J Dent. 2013;7(1):86-93.

PMid:23407620

5. Imazato S, Chen JH, Ma S, Izutani N, Li F. Antibacterial resin monomers based on quaternary ammonium and their benefits in restorative dentistry. Jpn Dent Sci Rev. 2012;48(2):115-25. https://doi.org/10.1016/j.jdsr.2012.02.003

6. Takahashi Y, Imazato S, Kaneshiro AV, Ebisu S, Frencken JE, Tay FR. Antibacterial effects and physical properties of glassionomer cements containing chlorhexidine for the ART approach. Dent Mater. 2006;22(7):647-52. https://doi.org/10.1016/j. dental.2005.08.003

PMid: 16226806

7. Denis $A B$, Diagone CA, Plepis AM, Viana RB. Kinetic parameters during Bis-GMA and TEGDMA monomer polymerization by ATR-FTIR: The influence of photoinitiator and light curing source. J Spectrosc. 2016;2016:6524901. https:// doi.org/10.1155/2016/6524901

8. Conde MC, Zanchi $\mathrm{CH}$, Rodrigues-Junior SA, Carreno NL, Ogliari FA, Piva E. Nanofiller loading level: Influence on selected properties of an adhesive resin. J Dent. 2009;37(5):331-5. https://doi.org/10.1016/j.jdent.2009.01.001

PMid: 19203819

9. Brochier Salon MC, Belgacem MN. Hydrolysis-condensation kinetics of different silane coupling agents. Phosphorus Sulfur Silicon. 2011;186(2):240-54. https://doi.org/10.1080/10426507. 2010.494644

10. Atai M, Pahlavan A, Moin N. Nano-porous thermally sintered nano silica as novel fillers for dental composites. Dent Mater. 2012;28(2):133-45. https://doi.org/10.1016/j.dental.2011.10.015 PMid:22137937

11. Du M, Zheng Y. Modification of silica nanoparticles and their application in UDMA dental polymeric composites. Polym Compos. 2007;28(2):198-207. https://doi.org/10.1002/pc.20377

12. American National Standards Institute. American National Standard/American Dental Association Specification No. 27 for Resin-Based Filling Materials. United States: American National Standards Institute; 1993. https://doi.org/10.14219/ jada.archive.1982.0296

13. Abed YA, Sabry HA, Alrobeigy NA. Degree of conversion and surface hardness of bulk-fill composite versus incrementalfill composite. Tanta Dent J. 2015;12(2):71-80. https://doi. org/10.1016/j.tdj.2015.01.003

14. Neves PB, Agnelli JA, Kurachi C, Souza CW. Addition of silver nanoparticles to composite resin: Effect on physical and bactericidal properties in vitro. Braz Dent J. 2014;25(2):141-5. https://doi.org/10.1590/0103-6440201302398 PMid:25140719

15. Ashby MF. Materials Selection in Mechanical Design. Burlington, MA: Butterworth-Heinemann; 2011. p. 142-6.

16. Randolph LD, Palin WM, Bebelman S, Devaux J, Gallez B, Leloup $\mathrm{G}$, et al. Ultra-fast light-curing resin composite with increased conversion and reduced monomer elution. Dent Mater. 2014;30(5):594-604. https://doi.org/10.1016/j. dental.2014.02.023

PMid:24679406 
17. Borges AF, Chase MA, Guggiari AL, Gonzalez MJ, de Souza Ribeiro AR, Pascon FM, et al. A critical review on the conversion degree of resin monomers by direct analyses. Braz Dent Sci. 2013;16(1):18-26. https://doi.org/10.14295/bds.2013.v16i1.845

18. Elhawary AA, Elkady AS, Kamar AA. Comparison of degree of conversion and microleakage in bulkfill flowable composite and conventional flowable composite (an in vitro study). Alex Dent J. 2016;41(3):336-43. https://doi.org/10.21608/ adjalexu.2016.58049

19. Ferracane JL. Current trends in dental composites. Crit Rev Oral Biol Med. 1995;6(4):302-18.

PMid:8664421

20. Peutzfeldt A. Resin composites in dentistry: The monomer systems. Eur J Oral Sci. 1997;105(2):97-116. https://doi. org/10.1111/j.1600-0722.1997.tb00188.x PMid:9151062

21. Par M, Spanovic N, Tauböck TT, Attin T, Tarle Z. Degree of conversion of experimental resin composites containing bioactive glass 45S5: The effect of post-cure heating. Sci Rep. 2019;9(1):17245. https://doi.org/10.1038/ s41598-019-54035-y

PMid:31754180

22. Chen $\mathrm{MH}$. Update on dental nanocomposites. J Dent Res. 2010;89(6):549-60.

PMid:20299523
23. Antonucci JM, Dickens SH, Fowler BO, Xu HH, McDonough WG. Chemistry of silanes: Interfaces in dental polymers and composites. J Res Natl Inst Stand Technol. 2005;110(5):54158. https://doi.org/10.6028/jres.110.081 PMid:27308178

24. Shamszadeh S, Akhavan ZV, Mofidi M, Abdo TM, Yazadani S. Comparison of Flexural Strength of Several Composite Resins available in Iran; 2013. p. 97-103. Available from: sid.ir/en/ journal/ViewPaper.aspx?id=502395.

25. Zorzin J, Maier E, Harre S, Fey T, Belli R, Lohbauer U, et al. Bulk-fill resin composites: Polymerization properties and extended light curing. Dent Mater. 2015;31(3):293-301. https:// doi.org/10.1016/j.dental.2014.12.010

PMid:25582061

26. Stencel R, Kasperski J, Pakieła W, Mertas A, Bobela E, Barszczewska-Rybarek $\mathrm{l}$, et al. Properties of experimental dental composites containing antibacterial silver-releasing filler. Materials (Basel). 2018;11(6):1031. https://doi.org/10.3390/ ma11112173

PMid:29912158

27. Halvorson RH, Erickson RL, Davidson CL. The effect of filler and silane content on conversion of resin-based composite. Dent Mater. 2003;19(4):327-33. https://doi.org/10.1016/ s0109-5641(02)00062-3

PMid:12686298 